\title{
繁 \\ Sarcocystis falcatula em papagaio-do-congo (Psittacus erithacus): relato de caso
}

[Sarcocystis falcatula on the Congo parrot (Psittacus erithacus): case report]

"Relato de Caso/Case Report"

Camille Erdmann Adão ${ }^{1 *}$, Bruna Gabrielle Pianta Brisqueleal ${ }^{1}$, Carolain Shorr Daga ${ }^{1}$, Ronaldo Piccoli $^{2}$, Monica Regina Matos ${ }^{1}$

${ }^{1}$ Laboratório de Patologia Veterinária, Universidade Federal do Paraná, Palotina-PR, Brasil.

${ }^{2}$ Departamento de Medicina Veterinária, Pontifícia Universidade Católica do Paraná, Toledo-PR, Brasil.

*Autora para correspondência/Corresponding author: E-mail: camilleerdmann16@gmail.com

\section{Resumo}

Sarcocystis falcatula é responsável por prover a doença parasitária sarcosporidiose. O gênero possui cerca de 130 espécies, sendo classificadas quanto a sua patogenicidade. Apresenta-se sob a forma de oocistos, bem como cisto tecidual nos hospedeiros intermediários acometidos, sendo alojados em órgãos diversos, podendo levar o hospedeiro intermediário a óbito súbito sem sinais clínicos prévios. O presente relato tem por objetivo descrever um caso de sarcosporidiose em papagaio-do-congo (Psittacus erithacus). Os fragmentos colhidos foram clivados histologicamente e corados pela coloração padrão H\&E. Na necropsia observou-se quadro hemorrágico pulmonar e encefálico. Na histologia, além do quadro hemorrágico, foram observadas em cortes de pulmão, estruturas protozoárias que foram classificadas como $S$. falcatula. Conclui-se que é necessária a disposição de mais materiais informativos considerando a popularização da adoção de pets exóticos, garantindo sanidade a estes.

Palavras-chave: sarcosporidiose; doença; protozoário; aves; histologia.

\begin{abstract}
Sarcocystis falcatula is responsible to cause the parasitic disease sarcosporidiosis. The genus has about 130 species, classified according to their pathogenicity. It is presented in the form of oocysts in the definitive host, and as tissue cysts at several organs in the affected intermediate host, which can lead the intermediate host to sudden death without previous symptoms. This present report describes a case of sarcosporidiosis in a Congo Parrot (Psittacus erithacus). Tissue fragments were trimmed histologically and stained with standard H\&E stain. At necropsy, pulmonary and brain hemorrhage was observed. Histologically, in addition to the hemorrhage, protozoal structures diagnosed as $S$. falcatula were seen in the lung. Considering the increasing in adoption of exotic pets, it is necessary to have more accessible information about them to the public, in order to guarantee their welfare.
\end{abstract}

Keywords: sarcosporidiosis; disease; protozoan; birds; histology.

\section{Introdução}

Sarcocystis falcatula é um protozoário pertencente ao filo Apicomplexa e é responsável pela manutenção da doença parasitária sarcosporidiose em aves diversas e em gambás do gênero Didelphis sp. A doença possui significativa relevância quando observada suas características de apresentação, comumente gerando um quadro de caráter agudo ou hiperagudo, levando as aves do Velho Mundo a uma morte súbita. $\mathrm{O}$ tratamento torna-se dificultado pela escassez de tempo hábil para emprego de terapêutica eficaz, devido à pouca ou 
ausente sinais clínicos apresentados (Valadas et al., 2016).

Sarcocystis falcatula é responsável por desenvolver um quadro doentio predominantemente respiratório nas aves ornamentais, tendo como principal sinal clínico a dispneia. Aves de caráter nativo, normalmente coexistentes ao hospedeiro definitivo, o gambá do gênero Didelphis sp., passam pela doença pulmonar e são passíveis de desenvolver, caso não tratadas, quadros de miosite, sinais neurológicos e emagrecimento progressivo, comumente acompanhados de espleno e hepatomegalia, bem como edema e congestão de órgãos diversos (Godoy et al., 2009).

Algumas aves nativas, como a araravermelha (Ara chloropterus) e aves pertencentes às ordens Anseriformes e Galliformes, como os patos e galinhas, respectivamente, são resistentes a afecções causadas por esse protozoário. Essa característica pode ser provinda da coexistência das aves com o hospedeiro definitivo em regiões endêmicas do país (Valadas et al., 2016).

A referida espécie protozoária é responsável por prover essa enfermidade de cunho importante quando se tratam de aves exóticas, em especial aquelas presentes em cativeiro. Considerando que essas aves tendam a ser naturalmente mais susceptíveis a infecções causadas pelo protozoário (Godoy et al., 2009), a afecção se apresenta na forma hiperaguda, frequentemente culminando com o óbito dessas aves.

Técnicas de diagnóstico pós-mortais, como a histologia, podem ser complementadas com técnicas moleculares como o PCR ou com técnica de imuno-histoquímica. A realização da Reação em Cadeia da Polimerase (PCR) é indicada para tipificação do parasito (Gondim et al., 2019).

Medidas de controle e profilaxia se fazem de suma importância para garantir o bem-estar e higidez dessas aves em cativeiro, uma vez que tal ambiente propicie melhores condições sanitárias e epidemiológicas, favorecendo assim, um controle significativo do ambiente e consequentemente um controle microbiológico, bem como outros animais contactantes, como o hospedeiro definitivo, dessa forma, assegurando um ambiente favorável para as aves (Nakasato et al., 2008).

Visando a importância que essa doença possui sobre a taxa de mortalidade em animais exóticos e alta prevalência do parasita em hospedeiros intermediários e aves silvestres, o objetivo deste relato é elucidar as lesões de cunho macro e microscópico a respeito da sarcosporidiose em um papagaio-do-congo.

\section{Descrição do Caso}

De acordo com o tutor, um papagaio-docongo (Psittacus erithacus), fêmea, dez meses de idade, possuía acesso a contactantes, sendo outras duas aves da espécie arara-canindé (Ara ararauna) e arara-vermelha (Ara chloropterus) no local em que residia. As aves contactantes apresentavam-se bem clinicamente. O espécime em questão não apresentou doenças anteriores e estava se alimentando normalmente, porém teve um mal súbito que culminou com a morte, sendo encaminhada à necropsia. A suspeita clínica era de trauma encefálico.

Durante a necropsia foram coletados fragmentos de rim, baço, pulmão, fígado $\mathrm{e}$ encéfalo, sendo fixadas em formol tamponado a $10 \%$, depois de fixados, as amostras foram clivadas e processadas histologicamente e coradas pela coloração padrão Hematoxilina-Eosina, procedida com leitura das lâminas em microscópio óptico (Tolosa et al., 2003).

$\mathrm{Na}$ necropsia, notou-se que o animal (Figura 1A) se apresentava moderadamente magro (moderada musculatura peitoral, com leve evidenciação da quilha e leve depósito de gordura na cavidade celomática, próxima do intestino). As mucosas oculares e oral apresentavam-se intensamente cianóticas. Havia hepato e esplenomegalia associada à congestão moderada hepática. Os rins apresentavam-se levemente congestos. O conteúdo intestinal era constituído de material pastoso esverdeado.

Os pulmões encontravam-se difusamente avermelhados, pesados, com aspecto úmido e brilhante, fluindo moderada quantidade de líquido espumoso brancacento até o terço médio da traqueia, sugerindo um edema pulmonar (Figura 1B). Em ambos os pulmões, notou-se moderada deposição de material filamentoso esbranquiçado sobre a superfície, induzindo a forte suspeita de pleurite fibrinosa. Observaram-se hemorragias multifocais moderadas nos lobos caudais dos pulmões.

Percebeu-se hemorragia sub meníngea focalmente extensa acentuada. As leptomeninges apresentaram-se hiperêmicas de forma difusamente acentuada, associado a achatamento e edema do telencéfalo (Figura 1C). 
Microscopicamente, notou-se no interstício renal a presença de infiltrado multifocal predominantemente mononucleado, associada a hiperemia difusa acentuada. No baço, pode-se perceber distensão difusa severa da polpa vermelha (congestão), associado à granulopoiese intramedular multifocal moderada e presença de pigmento marrom intra-macrofágico multifocal moderado (hemossiderina).

No pulmão, observou-se congestão difusa intensa do tecido com presença de material amorfo eosinofílico acentuado no lúmen dos parabrônquios e átrios (edema pulmonar) (Figura 1D), apresentando também áreas multifocais com intensa hemorragia que obliteram o lúmen de capilares aéreos, átrio e parabrônquios. Moderados macrófagos espumosos foram observados no lúmen dos parabrônquios. Notou-se grande quantidade de merozoítos encontrados no interior do endotélio dos capilares sanguíneos. Havia moderados esquizontes contendo merozoítos (Figura 1E). Estas estruturas foram classificadas como Sarcocystis falcatula.
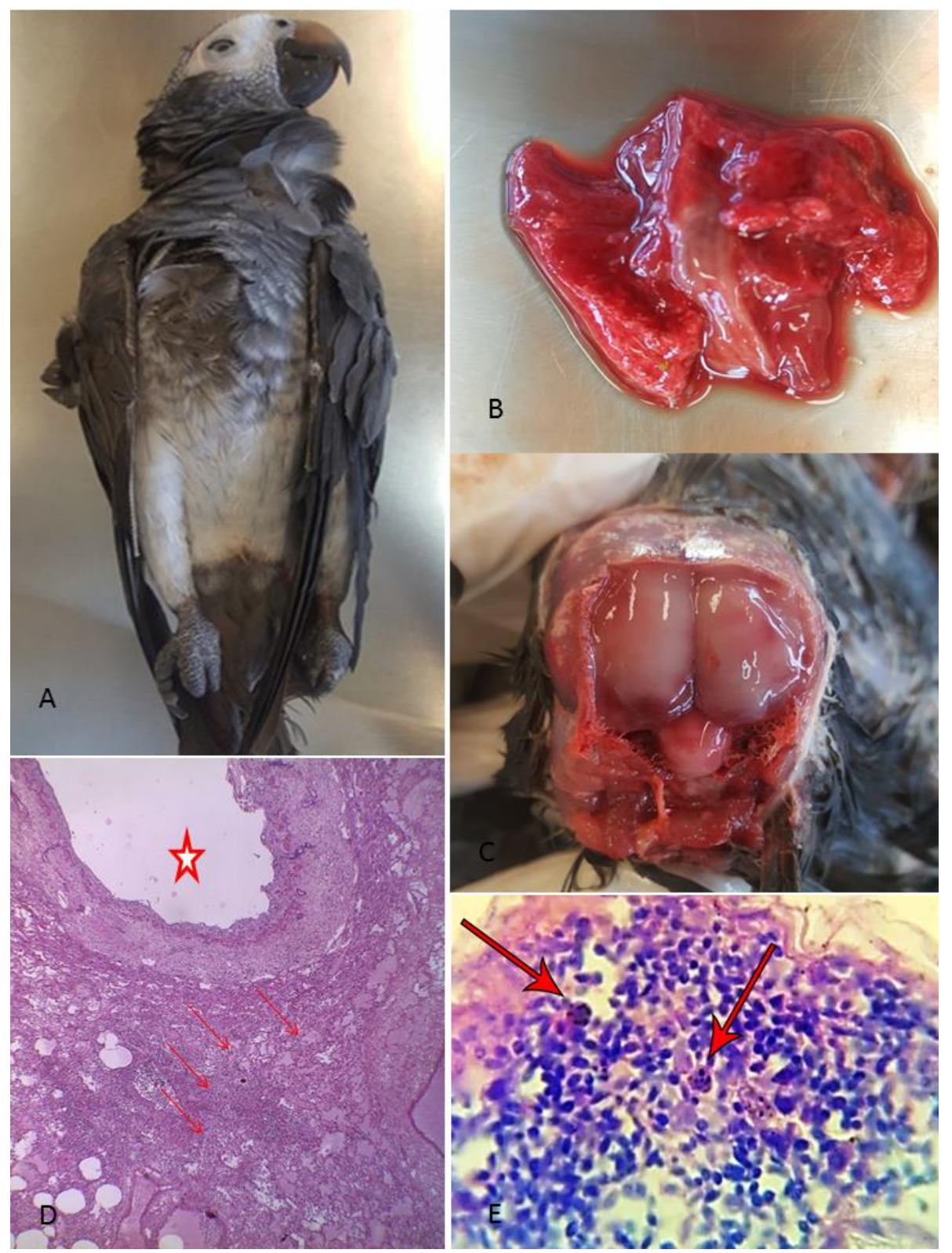

Figura 1. A: Cadáver de ave papagaio-do-congo (Psittacus erithacus). B: Pulmão do papagaio-do-congo. Notar aspecto brilhante, avermelhado e úmido. C: Encéfalo do papagaio-do-congo. Notar achatamento e edema de telencéfalo e hemorragia encefálica. D: Histologia do pulmão (estrela indica parabrônquio) do papagaio-do-congo. Observa-se intenso material amorfo eosinofílico (edema) e acentuadas hemácias (hemorragia) no lúmen dos capilares aéreos (setas). Coloração H\&E obj. 4x. E: Histologia do pulmão do papagaio-do-congo. Há grande quantidade de merozoítos. Há moderados esquizontes contendo alguns merozoítos (setas). Estas estruturas foram classificadas como Sarcocystis falcatula. Coloração H\&E obj. 40x. 
Ao analisar o fígado, notou-se, entremeado aos hepatócitos e obstruindo os capilares sinusoides hepáticos, infiltrado inflamatório multifocal a coalescente acentuado de linfócitos, histiócitos, raros heterófilos e plasmócitos. Apresentou leve aumento da eosinofilia citoplasmática e picnose nuclear (necrose individual). Os hepatócitos adjacentes apresentavam vacuolização citoplasmática delicada com discreta marginação nuclear para a periferia das células (esteatose). Por vezes, houve retenção multifocal discreta a leve de material castanho dourado no citoplasma dos hepatócitos (processo colestásico).

O encéfalo apresentava hemorragia sub meningeal multifocal a coalescente acentuada, bem como congestão difusa acentuada dos vasos, associada a raros depósitos de fibrina $\mathrm{e}$ perivasculite linfohistioplasmocitária multifocal acentuada. No córtex do telencéfalo notou-se neurônios com citoplasma intensamente eosinofílicos e núcleo picnótico (necrose neuronal). Constatou-se aumento difuso moderado das células gliais no neurópilo (astrocitos, oligodentrócitos e migróglia).

\section{Discussão}

Os protozoários contidos dentro da espécie Sarcocystis sp são capazes de acometer espécies animais diversas, como mamíferos, répteis a aves. Os hospedeiros definitivos - gambás do gênero Didelphis sp - são capazes de albergar mais de uma espécie do parasito concomitantemente em seu trato digestivo. Bem como, diversas variações dos referidos protozoários, não apresentam predileção por espécies específicas do hospedeiro definitivo (Gondim et al., 2019), sendo assim, os meios de propagação são favoráveis para manutenção da enfermidade no ambiente, podendo acometer um elevado número de animais e, consequentemente, induzi-los a óbito agudo, como observado neste caso.

As aves do Velho Mundo apresentam maior susceptibilidade ao parasito quando comparadas a aves do Novo Mundo e aves nativas (Godoy et al., 2009). Tal fator pode ser correlacionado a coexistência entre as aves nativas e o hospedeiro definitivo. A referida teoria sustenta a apresentação do quadro do presente relato, sendo uma ave do Velho Mundo e exótica na fauna brasileira papagaio-do-congo (Psittacus erithacus), coincidindo com o relatado por Kirejczyk et al. (2019), onde três pinguins desenvolveram pneumonia fatal, apresentando elevado número de parasitos observados em cortes histológicos de pulmão, associado a outras alterações como edema e infiltrado inflamatório, achados também presentes neste relato.

O papagaio-do-congo (Psittacus erithacus), sendo uma ave exótica, está susceptível a tal infecção parasitária. As aves da ordem Psittaciformes representam a classe com maior número de afecções gerais. A sarcosporidiose fazse presente em aves exóticas brasileiras (considerando as aves de vida em cativeiro, uma vez que o acometimento de aves de vida livre infelizmente seja dificilmente quantificado) também sendo uma das várias causas de doenças com apresentação de quadros respiratórios em aves exóticas distribuídas por toda a extensão do país, possuindo sinais clínicos em comum com outras doenças, como afecções fúngicas $\mathrm{e}$ bacterianas (Santos et al., 2008).

Em relato descrito por Godoy et al. (2009) um total de 47 psitacídeos alojados em cativeiro em Foz do Iguaçu, Paraná, Brasil, morreram em um período de 15 meses durante um surto de infecção por S. falcatula nos anos de 2005-2006. $\mathrm{O}$ cativeiro é localizado em uma área natural de floresta tropical habitada por muitos gambás e localizada cerca de $150 \mathrm{~km}$ da localidade do presente caso. No relato, as aves apresentaram quadro hemorrágico pulmonar e estruturas parasitárias compatíveis com S. falcatula, como neste caso.

Segundo Gonçalves et al. (2016), macroscopicamente são observados edema e congestão de órgãos diversos, considerando que inicialmente o protozoário esteja localizado na circulação sanguínea, a probabilidade de distribuição generalizada do mesmo é significativa, justificando tais lesões em órgãos com maior irrigação sanguínea, como fígado, baço, coração, pulmões, rins e encéfalo. $\mathrm{O}$ exemplar necropsiado apresentou as lesões macroscópicas fidedignamente conforme apresentado na literatura, bem como seus caracteres microscópicos (histológicos) seguiram o mesmo padrão.

Histologicamente, o espécime em questão apresentava a presença de intenso infiltrado inflamatório predominantemente mononucleado em todos os órgãos encaminhados para análise histológica, associada a presença de merozoítos em cortes de pulmão, como descrito por Kirejczyk et al. (2019), sendo os mesmos classificados como 
a espécie protozoária em questão. Associando-se os achados histológicos, história clínica do animal e da espécie do mesmo, pôde-se concluir que os achados são condizentes com aquilo disposto na literatura, indicando que a doença em questão sugere fortemente que se trate de um caso de sarcosporidiose.

A escassez no campo de pesquisa referente à sarcosporidiose causada pela $S$. falcatula em aves exóticas pode ser justificada pelo comportamento hiperagudo que a doença exerce, podendo muitas vezes não ser corretamente diagnosticada clinicamente devido ao curto intervalo de tempo entre a manifestação clínica e o óbito do animal, como observado neste relato (Valadas et al., 2016).

\section{Conclusão}

Sarcocystis falcatula é uma espécie protozoária que merece maior enfoque no âmbito de pesquisa relacionado a doenças respiratórias e sistêmicas de aves. Considerando a maior ocorrência de escolha de animais exóticos, em especial aves como animais de estimação, faz-se necessária a disposição de mais materiais com caráter informativo. Novas pesquisas bem como a utilização de técnicas diagnósticas moleculares, possibilitariam melhores medidas de controle e profilaxia para redução da ocorrência de novos casos da doença, proporcionando assim condições favoráveis a higidez desses animais.

\section{Conflito de interesse}

Os autores declaram não existir conflito de interesse.

\section{Referências}

Godoy, S.N.; Paula, C.D.; Cubas, Z.S.; Matushima, E.R.; Catão-dias, J.L. Occurrence of Sarcocystis falcatula in captive psittacine birds in Brazil. Journal of Avian Medicine and Surgery, 23(1): 18-23, 2009.

Gonçalves, S.P.; Aragão, K.C.G.; Takeda, G.K.F. Pesquisa de sarcocistos de Sarcocystis spp na musculatura bovina. Atas de Ciências da Saúde, 4(1): 39-49, 2016.

Gondim, L.F.; Soares, R.M.; Tavares, A.S., Silva, W.B.; Jesus, R.F.; Llano, H.A.B.; Gondim, L.Q. Sarcocystis falcatula-like derived from opossum in northeastern Brazil: in vitro propagation in avian cells, molecular caracterization and bioassay in birds. IJP: Parasites and Wildlife, 10: 132-137, 2019.

Kirejczyk, S.G.M.; Burns, R.E.; Hyatt, M.W.; Yabsley, M.J.; Beest, J.M.T.; Gyimesi, Z.S.; Ossiboff, R.J.; Waltman, A.; Seimon, T.A.; McManamon, R. Fatal Sarcocystis falcatula infection in three penguins. Frontiers in Veterinary Science, 6(340): 1-8, 2019.

Nakasato, F.H.; Saito, A.S.; Taneno, J.C.; Garcia, M.M.; Neves, M.F. Sarcocystis spp: revisão de literatura. Revista Científica Eletrônica de Medicina Veterinária, 6(11): 1-6, 2008.

Santos, G.G.C.; Matuella, G.A.; Coraiola, A.M.; Silva, L.C.S.; Lange, R.R.; Santin, E. Doenças de aves selvagens diagnosticadas na Universidade Federal do Paraná (2003-2007). Pesquisa Veterinária Brasileira, 28(11): 565-570, 2008.

Tolosa, E.M.C.; Rodrigues, C.J.; Behmer, O.A.; Freitas Neto, A.G. Manual de técnicas para histologia normal e patológica. $2^{\mathrm{a}}$ ed. Barueri: Manole. 2003. 341p.

Valadas, S.Y.O.B.; Soares, R.M.; Lindsay, D.S. A review of Sarcocystis spp. shed by opossums (Didelphis spp.) in Brazil. Brazilian Journal of Veterinary Research and Animal Science, $\quad$ 53(3): 2016. 